\title{
Investigation on the Ecological Environment and Resource Protection Management System of Fuxian Lake
}

\author{
Xianhua Wu ${ }^{1}$, Ke Deng ${ }^{2}$, Ping Ge ${ }^{3}$, Yue Wang ${ }^{4}$, Yadong Xue \\ ${ }^{1,3,4}$ Yuxi Research Center for Eco-environmental Sciences on Plateau Lakes, Yuxi Normal Univesity, Yuxi \\ Yunnan, 653100, China \\ ${ }^{2}$ Yuxi Fuxian Lake Protection Development Investment Company, LTD, Yuxi Yunnan, 653100, China \\ ${ }^{5}$ Yuxi center for disease Control And prevention, Department for the Sanitary Monitoring And \\ Test, Yuxi Yunnan, 653100,China
}

Keywords: Fuxian Lake, Environmental problem, Controlling measure, Management system.

\begin{abstract}
Fuxian Lake is one of the few lakes with Class I water quality at present in China, it is a typical representative of a poor nutrition lake. The author attended "Yunnan social scientists investigate in Yuxi" research and consulting activity, through this concentrated investigation, discussion, communication and analysis, visited 22 research points, investigated 12 trail projects, the survey result is as following:
\end{abstract}

\section{Strategic status and importance of Fuxian Lake}

\section{Water storage is the first in inland lakes in China}

Fuxian lake is the largest deep water type fresh water lake in our country, it is the clearest and most transparent lake in the Yungui plateau, it is famous for its excellent water quality, natural steep rock lake shore and healthy lake ecosystem, is one of the few class I water quality lakes in China, is the typical representative of a few poor nutrition lakes in the relatively developed areas of China. The lake basin area is 674.69 square kilometers, water area is 216.6 square kilometers, the maximum depth is $158.9 \mathrm{~m}$, average depth of 95.2 meters; the volume of water storage reaches 20.62 billion cubic meters, it's 12 times that of the Dianchi Lake, 7 times that of Erhai Lake, 6.4 times that of Chaohu Lake, 4.5 times that of Taihu Lake, it accounts for $9.16 \%$ of the water storage of national freshwater lake, accounts for $68 \%$ of the water storage of the nine largest plateau lakes in Yunnan province. The water resource of Fuxian Lake is of great significance to the economic and social development of Yuxi city, it also has a big national impact, has an important strategic position in the pearl river delta.

\section{China's important strategic reserve water source}

Important ecological barriers in the Pearl River Basin and the southwest-Fuxian Lake is located at the source of the Pearl river, its ecological system has unique ecological environment and species, has special fishes in the Pearl river, such as Chang's Barbudes Caldwell, Yunnan Spinibarbus denticulatus, Fuxian Schizothorax, Gagata cenia and Cross-watershed Barbodes elongates, Yunnan Acrossocheilus fasciatus, Discogobio yunnanensis, Cyprinus carpio chilia, side lines loach and Rasbora gerlachi. The dominant species of aquatic plants, phytoplankton, zooplankton and benthic animals are mainly water-based, thereinto, there are 12 kinds of submerged plants with the advantage of bitter grass, located in an area of 0 to 3 meters offshore; phytoplankton community structure is dominated by green algae and diatoms, totally 40 kinds; zooplankton dominant species are copepods. Healthy ecosystems play an important role in biodiversity conservation, water conservation, soil conservation and climate regulation, $\mathrm{i} t$ is an important barrier to the Pearl river source and the ecological safety of the southwest. 


\section{China's scarce and unique precious resources}

The water body of Fuxian lake keeps Class I quality, which is rare in China. Fuxian lake is an important and rare lake in China, from the total water resources of fresh water lake, it ranks first in the country, its resources account for $9.16 \%$ of the total water resources of freshwater lakes in China, the amount of fresh water is more than the total amount of fresh water in the plain lake area of northeast China, almost reaches $70 \%$ to $80 \%$ of the total fresh water in important lakes in the middle and lower reaches of the Yangtze river. And Fuxian lake water quality is still in class I, average transparency is 5-6 meters, the maximum is $12.5 \mathrm{~m}$, it is one of the few high quality freshwater lakes in China. Such a good lake is rare in China.

\section{Ecological environment and key problems of Fuxian lake}

\section{Water quality has been declining and environmental ecological problems still exist}

Overall water quality change trend

Although water quality of Fuxian Lake remains in class I, due to the long-term accumulation of environmental pollution problems, its water quality once has been falling from class I to class II, even to the critical state of emergency water class I(northern, southern and pollution areas along the lake). At present, average value of total nitrogen has already very close to the upper limit of class I water quality, water quality of coastal part has already in class II, and there are trends from north to south, from coast to the middle of the lake, the risk of lake water quality declining from quantitative to qualitative change is increasing, Fuxian lake is facing a serious environmental ecological problem.

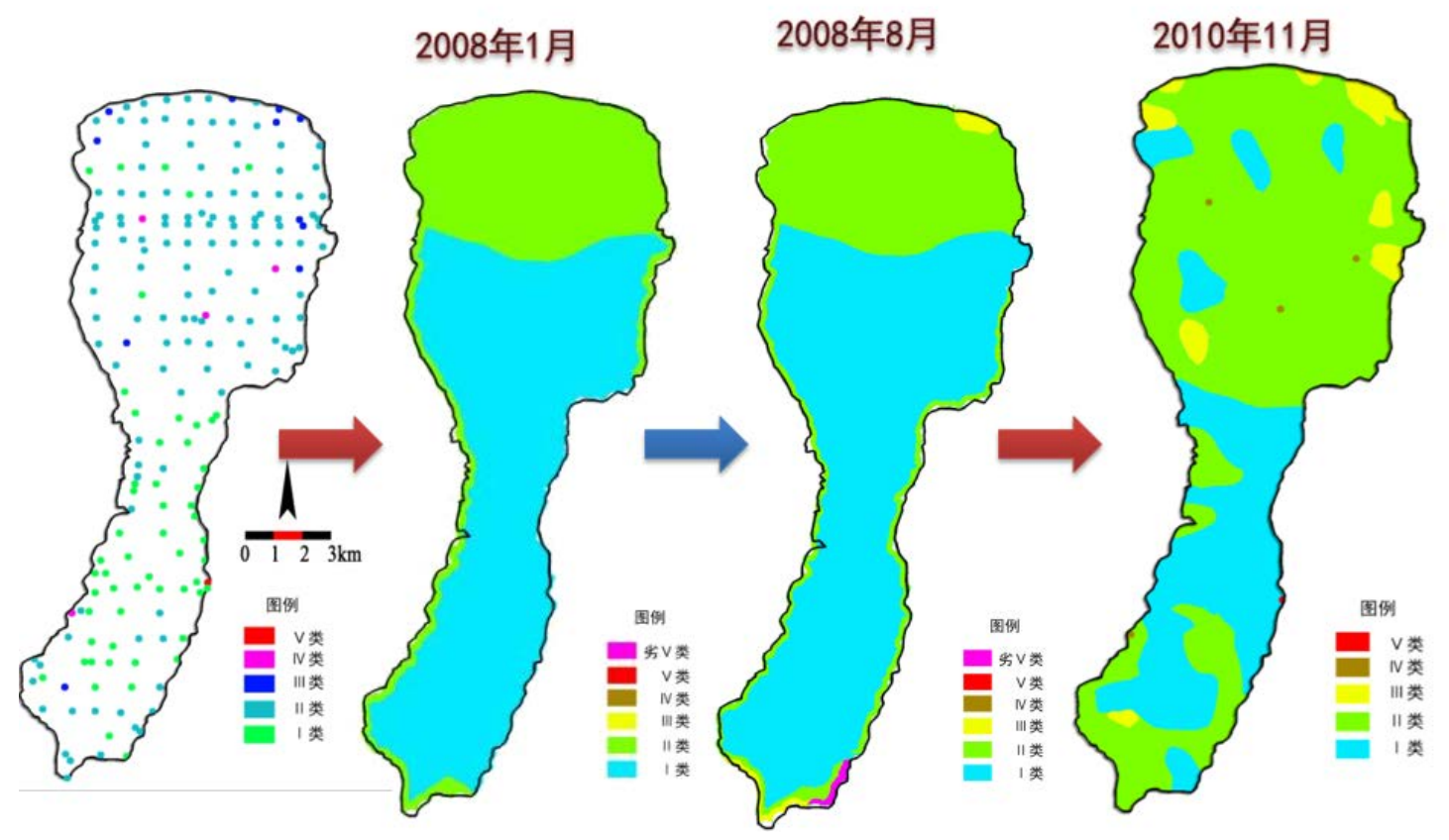

Fig. 1. Water quality of Fuxian Lake during the drought in 2008-2011 


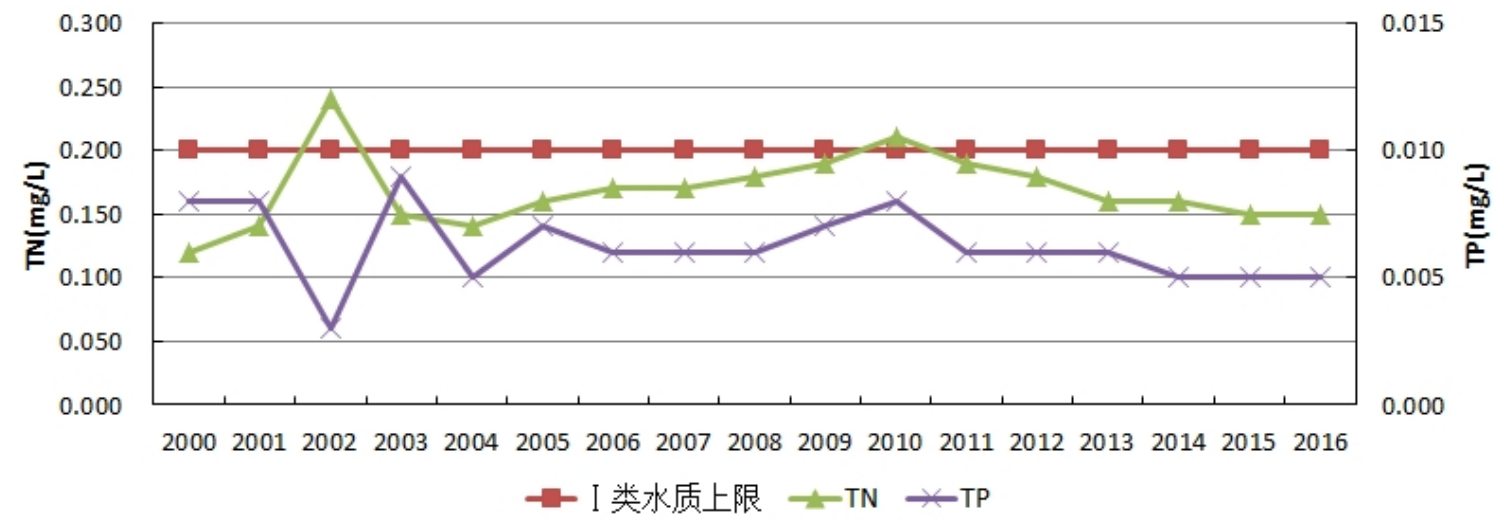

Fig. 2. Changes of total nitrogen (TN), total phosphorus (TP) of Fuxian Lake in 2000-2016

The present situation of ecological environment of Fuxian lake

The ecological environment of Fuxian Lake is fragile, the land area of the runoff area is only twice that of the water area, the catchment area is small and no water catchment, theoretical changing water period is over 200 years, surface mountain forest coverage is low, desertification and soil erosion are serious; runoff area has a large population density, agricultural recovery index is nearly $400 \%$; the natural bank of the lake is generally subject to human intervention, self-purification function of lake beach was seriously damaged; the lake water ecosystem has seen the trend of decrease of water species, the increase of anti-pollution, the invasion of alien species, the extinction of native species and increase of the nutrition of the water body, the biodiversity of lake biological lakes has been greatly challenged.

\section{The key issues should be emphasized}

1. Effectively control the pollution source in the basin (urban and rural sewage, rubbish collection and disposal), nearly 30 class VI water source into the lake, lakeside population and so on, to ensure that the pollution of Fuxian Lake is lower than that of the environmental loading ability of lakes.

2. Scientific, vigorously and orderly adjust the industrial structure of Fuxian Lake runoff area, implement ecological remediation, environment supervision, wetland park construction, structural reform, multiple investment and other works.

3. Continue to monitor, evaluate and early warn water ecological change, timely grasp algae amount, chlorophyll and other elementary productivity of lake, and adopt scientific and effective pertinence measures.

4. Continue to monitor, evaluate and early warn water quality, timely grasp down trend from class I to class II, and adopt scientific and effective pertinence measures.

\section{Protection and governance system for ecological environment and resources of Fuxian Lake and its operation effect}

\section{Protection and governance system}

Yuxi city has been adhering to engineering measures and non-engineering measures for many years, set water environment carrying capacity, the main pollutants into the lake emission reduction and distribution as core to set up three-level sewage water control and management system and mode that consists of drainage basin, control area and control unit; take the lead in national practice of new concept of lake conservation and governance "green watershed protection, clean water flow mechanism and the lake shore buffer zone construction".

Organization. Established Fuxian Lake - Xingyun Lake ecological construction and tourism reform \& development comprehensive pilot zone management committee, published The decision to comprehensively strengthen the ecological civilization construction, the ecological construction and tourism reform \& development of Fuxian Lake and Xingyun Lake. 
Platform. Established investment and financing platform, cumulative implementation monetary financing 2.094 billion yuan, project financing 2.905 billion yuan, provided financial guarantee for Fuxian Lake eco-environmental protection project; built a technology support platform, hired three academicians and seven multidisciplinary high-level experts to form Expert Working Groups for Fuxian Lake Protection, from macroscopic view, give guidance for idea and concept for Fuxian Lake protection, from microscopic view, provide support for Fuxian Lake protection of management engineering technology.

Breakthrough. One is the breakthrough of protection and development, all the development projects in the core pilot area must strictly obey Fuxian Lake protection ordinance of Yunnan Province, Four red lines; second is that breakthrough of exploration of ecological compensation mechanism, begin to impose Fuxian Lake resource protection fee, set up pilot area project cash deposit and special fund system for Fuxian Lake protection and treatment, supervise and urge Fuxian Lake development enterprise to perform environmental responsibility; third is the breakthrough of industrial transformation and development, establish industry support fund, prioritize low pollution varieties like lotus, nursery-grown plant, blueberry and so on, gradually replace high pollution varieties like flowers and vegetables.

Mechanism. First is to establish clear aquatic flow mechanism, return the grain plots to forestry for slope land above 25 degrees around Fuxian Lake, and strengthen comprehensive treatment of water sources land, ensure plenty of water will go into the lake; second is to establish a linkage law enforcement mechanism, strictly investigate all kinds of irregularity actions against Fuxian Lake protection ordinance of Yunnan Province; third to establish publicity education mechanism, accept social supervision, mobilize social participation; fourth to establish assessment accountability mechanism, formulate strict measures for administrative accountability, to implement the protection responsibility of Fuxian Lake.

Engineer construction. The first is to implement ecological restoration projects; second to implement the pollution control project; third to implement pollution control project; forth to implement main river channel improvement works; fifth to strengthen ecological safety management in the basin.

\section{Operation effect}

Fuxian Lake is brought into national parks system, construction of national wetland park pilot

Fuxian Lake drainage basin is brought into national ecological civilization advance demonstration area

According to The state council' opinion on accelerating the development of energy conservation and environmental protection industries, "choose 100 representative areas in the country to carry out ecological civilization advance demonstration area construction", December 2013, relevant department issued construction plan of national ecological civilization advance demonstration area (trial), choose areas at different development stage, endowment of resource environment to for trial to explore ecological civilization construction mode that accordance with Chinese conditions.

Three counties around Fuxian Lake is brought into the scope of transfer payment of key ecological functional areas of the state

According to the requirement of Environmental quality assessment work implementation plan for national key ecological functional areas in 2013, Chengjiang, Jiangchuan and Huaning, three counties around Fuxian Lake strengthened environmental protection, brought three counties into relevant department for research, in 2015, the three counties has already been brought into the scope of transfer payment of key ecological functional areas of National functional area planning and National ecological function zoning.

FuXian Lake runoff area has been brought into the scope of national small and medium-sized river administration and pilot of water ecological civilization construction

Two small and medium river management projects of Huaning county in Fuxian Lake runoff area have been brought into national small and medium-sized river administration planning, total investment of 35.31 million yuan, thereinto, central government invested 27.65 million yuan. The 
central investment has been arranged, two governance projects have been implemented. Yunnan provincial capital has multiple channels to raise capital, increased investment for $\mathrm{s}$ mall river administration work in the runoff area of Fuxian Lake.

Rocky areas of Fuxian Lake runoff area have been brought into national desertification control project

The State Council issued Comprehensive management plan of rock desertification in karst area (2006 2015) in February 2008 (hereinafter referred to as Comprehensive management plan), the project covers 451 pilot projects of integrated treatment of stony desertification in karst areas. The national development and reform commission has allocated 7.7 billion yuan for infrastructure investment, coordinate the restoration of vegetation, basic farmland and rural energy construction, ruminants husbandry and follow-up industry development, easy poverty alleviation and relocation and other engineering construction, effectively promoted the improvement of regional ecological environment.

Comprehensive water pollution control "the 12th"five year plan of Fuxian Lake runoff area has got a good performance

In 2016, Yunnan provincial nine plateau lakes comprehensive prevention and control of water pollution office organized relevant experts to evaluate the performance of "the 12th"five year plan (2011-2015)for prevention and control of water pollution of Fuxian Lake runoff area, the audition group through survey in all directions, debrief, accessing to information and questioning on water quality index, project construction, supervision and management, Fuxian Lake performance is good; the main reasons for the good result are its class I water quality, obvious improvement of water quality flowing into the lake, the fund appropriative rate and project completion rate of its watr pollution control reached $100 \%$, the municipal government implemented its supervision and management responsibilities.

Establish ecological compensation mechanism for Fuxian Lake runoff area to collect protection fund

Set out Yuxi City Fuxian Lake collection management method of resource protection fee, Implementation rules for the collection and management of resource protection fees, establish experiment area project security and special fund for Fuxian Lake protection and treatment and establish pultiple investment and financing platform mechanisms.

\section{The concept and method of pollution control of lake protection in UK, USA and China}

As China's point source pollution control rate has increased greatly, surface source pollution has become a key problem in improving water environment quality. Mastering the research and application progress of international and domestic lakes protection and management, making full use of our city as national sponge city construction pilot opportunity, to adapt local conditions to draw lessons from international pollution control, concept and method of surface greening and pollution control, continue to promote the protection and governance of Fuxian Lake.

\section{Suggestions to sustained and effectively contain large amounts of water, length of change of water cycle, small catchment area, high pollutant retention rate, maintain water quality in class I:}

(I) Party committees, government and relevant departments at all levels bear the environmental protection responsibility for Fuxian Lake, timely and correctly find out and solve key problems for the protection and management, fully implement entity responsibility of "The party and government bear same responsibility", "Two Duties for One Pos", to continue improving working mechanism of operating economic environment and resources protection on the basis of establishing 1 organization, setting up 2 platforms, realizing 3 breakthroughs, setting up 4 mechanisms, implementing 5 engineers to ensure ecological environment and tourism environment safety of Fuxian Lake.

(II) Seize the opportunity that Fuxian Lake resource environment comprehensive administrative law enforcement reform has been listed in national pilot, fully integrate law enforcement functions 
and team in every county, strengthen Fuxian Lake ecological environment and resource protection normalization, strengthen the organization and supervision strength of the priority, gradually fulfill duty, establish normalized inspection, supervision, guidance and evaluation work mechanism, take investigating environmental problems in accordance with the law as the main fulcrum for ecological environmental protection.

(III)Grasp the advanced concept and method for international and domestic lake protection and pollution control, sponge city construction, surface greening used to control pollution, fully display the demonstration and promotion of Fuxian Lake protection engineer; during the construction and operation process with strong profession, technicality, practicalness, to continue to strengthen survy, supervision, analysis, research, inspection, guidance and evaluation and well perform dynamic monitoring, evaluation and maintenance of ecological engineering operation effect.

(IV)Faithfully implement the $13^{\text {rd }}$ five-year plan for Fuxian Lake water pollution control, to realize keep class I water quality and the goal of "good environment, good industry, beautiful city, rich people and suitable system". Strictly control pollutant according to the water environment carrying capacity, guide town and country construction, tourist spot construction tourist area construction, industrial restructuring, ecomigration, ecological remediation, monitoring and early warning, supervision and administration to realize the sustainable development of society, economy and ecology.

\section{Acknowledgement}

Supported by Program for Innovative Research Team (in Science and Technology) in University of Yunnan Province, IRTSTYN201422.

\section{References}

[1] Wu Xianhua, Li Yinxi, Hou Changding. Analysis on the environmental status of Fuxian Lake, Journal of Yuxi Normal University, 2002(02).

[2] Deng Xinyan, Xu Jihong. Research on the algae in Fuxian Lake, Journal of Yunnan University(JCR Science Edition). 1996(02).

[3] Xiongfei, Li Wenchao, Pan Jizheng, Xia Tianxiang, Li Aiquan. Features of the distribution of submerged plants and community structure in Yunnan Fuxian Lake, Acta Botanica Yunnanica. 2006(03).

[4] Pan Jizheng, Xiongfei, Li Wenchao, Kefan. Structure, distribution and impact factors of phytoplankton in Fuxian Lake, Acta Ecologica Sinica. 2009(10). 